\title{
Concordance between school outcomes and developmental follow-up results of very preterm and/or low birth weight children at the age of 5 years
}

\author{
Boudien van Kessel-Feddema • Meta Sondaar • \\ Martin de Kleine • Christianne Verhaak • \\ Anneloes van Baar
}

Received: 18 June 2006 / Accepted: 5 September 2006 / Published online: 16 November 2006

(C) Springer-Verlag 2006

\begin{abstract}
Introduction Long-term follow-up studies have revealed a high frequency of developmental disturbances in preterm survivors of neonatal intensive care who were formerly considered to be non-disabled. These developmental disturbances interfere with the acquisition of everyday skills and, in particular, with normal school functioning.

Methods Developmental and school outcomes of 355 children, age 5 years at the time of the study, who had a mean gestational age of 30.2 weeks (SD: 1.95) and a mean birth weight of $1272 \mathrm{~g}$ (SD: 326) were investigated. Children with severe handicaps were excluded from the study. Perinatal data, information from a parental and school questionnaire and data from standardized developmental tests were used to explain the differences.

Results An agreement of $72 \%$ was found between developmental follow-up and school outcomes. Normal developmental results but problematic school outcomes were
\end{abstract}

The study was supported by a grant of the Praeventiefonds, project no. 28-2756 and Zorg Onderzoek Nederland (ZON), project no. 10010004-20.

B. van Kessel-Feddema $(\bowtie) \cdot$ M. Sondaar $\cdot$ C. Verhaak

Department of Medical Psychology,

Radboud University Nijmegen Medical Centre,

P.O. Box 9101, 6500 HB Nijmegen, The Netherlands

e-mail: b.vankessel@cukz.umcn.nl

M. de Kleine

Department of Neonatology, Máxima Medical Centre,

Veldhoven, The Netherlands

A. van Baar

Pediatric Psychology, Tilburg University,

Tilburg, The Netherlands found for $15 \%$ of the children tested. There were more boys than girls in this latter group as well as small-forgestational-age children with relatively poor motor or language development. The schools had not identified problems in $13 \%$ of the children, whereas their developmental outcomes were problematic. These children had less neonatal morbidity and relatively higher IQ's than children who also had problematic developmental outcomes but who had been signalled as problematic by their schools.

Conclusions Schools have a good insight in the school functioning of children who are developing well and of children with the lowest developmental scores and the most complicated neonatal histories. How school and developmental outcomes interrelate in the in-between groups remains a challenging question that could be answered by following these children throughout their school career.

Keywords Developmental outcome - Low birth weight children · Premature children - School outcome . School performance $\cdot$ Very preterm children

$\begin{array}{ll}\text { Abbreviations } & \\ \text { BPD } & \text { bronchopulmonary dysplasia } \\ \text { CBCL } & \text { Child Behaviour Checklist } \\ \text { GLM } & \text { General Linear Model } \\ \text { ICH } & \text { intracranial haemorrhage } \\ \text { IQ } & \text { Intelligent Quotient } \\ \text { Movement ABC } & \begin{array}{l}\text { Movement Assessment Battery for } \\ \text { Children }\end{array} \\ \text { NICU } & \text { neonatal intensive care centre } \\ \text { PVL } & \text { periventricular leucomalacia } \\ \text { RAKIT } & \text { Revised Amsterdam Children's } \\ & \text { Intelligence Test }\end{array}$




$\begin{array}{ll}\text { SES } & \text { social and economic situation } \\ \text { Small for gestational age } \\ \text { VLBW } & \text { very low birth weight } \\ \text { VPT } & \text { very preterm } \\ \text { WISC-R } & \text { Wechsler Intelligence Scale for } \\ & \text { Children-Revised }\end{array}$

\section{Introduction}

The survival rate of very preterm (VPT $<32$ completed weeks of gestation) and very low birth weight (VLBW $<1500 \mathrm{~g})$ children has steadily improved during the last decades, but the prevalence of major disabilities or handicaps in these children has remained stable. Follow-up studies have shown that VPT and VLBW infants are at risk with regard to neurological dysfunctioning such as cerebral palsy and mental retardation [6, 17, 31,33]. Even more children of these groups experience difficulties in intellectual, speech and language skills as well as clumsiness and attention and behaviour problems, all of which can affect school functioning $[4,12,13,16,19,24,26]$.

Significant/severe neurosensory dysfunctioning is usually detected early, with the result that children with major handicaps often attend a school for special education from school entry. Minor developmental impairments and disabilities, however, frequently go undetected until school age (4 years in The Netherlands). These children start their school career in mainstream education. Once at school, however, certain learning problems may become apparent during the first 2 years (the kindergarten years), but more often these appear only when the children start formal academic training $[15,22,34]$. Several reasons may explain this phenomenon of 'growing into educational deficits' $[2,9,18,20,27]$.

Mild developmental disturbances usually pose no problem for the child until greater demands have to be met at school or when more detailed evaluations are made. In addition, the cumulative effect of the failure to acquire basic skills and the resulting declining motivation may play an important role. In The Netherlands, schools are focused strongly on the early detection of children who need special assistance. After 1 year of education, at the age of 5 , teachers usually have a good impression of both the cognitive and language development of their children and of their motor skills and behaviour. Standardized tests are used to assess children who are not doing well at school, and the data from these tests are used to underpin the need for special help for these children. Additionally, many neonatal intensive care units (NICUs) have follow-up programmes for premature children in which standardized assessments of different domains enable an overall evaluation of the child's development.
Within the framework of follow-up research we assessed a group of VPT and VLBW children at the age of 5 years in different developmental domains. Perinatal, social and economic data as well as information on school functioning were available. This provided the opportunity to compare school outcomes and developmental follow-up outcomes, assuming that developmental skills mediate the effects of biological and social risk factors on school performance [35]. We studied the degree of agreement between followup assessments and school outcomes as well as the most important characteristics of the children (perinatal, developmental and socio-economic) in this context. Our aim was to obtain a understanding of the (potential) developmental disturbances in order to facilitate an adequate and timely signalling of children who need special help to meet their developmental capacities.

\section{Methods}

\section{Study population}

The study population consisted of 768 infants of less than 32 weeks of gestation and/or weighing less than $1500 \mathrm{~g}$ who were born between October 1992 and December 1994 and treated in three Dutch neonatal intensive care units: the Radboud University Nijmegen Medical Centre, the Academic Medical Centre, Amsterdam, and the Máxima Medical Centre, Veldhoven. Mortality before the age of 5 years was 131 (17\%). Forty-six children (6\%) were excluded because they had participated in another study. Thirty-three children (4\%) with severe or moderate cerebral palsy, blindness, mental retardation, chromosomal abnormalities, inborn errors of metabolism, personality developmental disorders and/or attendance at special schools or institutions were excluded. Sixty children $(8 \%)$ of nonDutch parents were excluded from the analyses since school problems could be caused by language and cultural problems. As a result, 498 children (65\%) qualified for the study.

School performance and socio-economic situation

A questionnaire was mailed to the parents of the participating children 1 month before follow-up assessments were to be carried out; these were returned when the family attended the outpatient clinic for the assessment. The paediatrician initiated the follow-up assessment by checking the questionnaire and exploring the answers with the family in more depth. Within the framework of the present study we analysed questions addressing school performance and educational level of the parents (low, middle, high). School outcome was defined in two categories: (1) normal 
(mainstream education without problems, which means no remedial teaching or other forms of extra help) or (2) problematic (mainstream education with remedial teaching or special mainstream education; i.e. schools for children with mild learning, behavioural or cognitive problems). The parents were asked to fill in the school items together with the schoolteacher. The educational level of the parents was used in this study as a measure of the social and economic situation (SES) because it is the best indicator in predicting school outcomes in The Netherlands [5].

Perinatal data

Perinatal data were prospectively collected during admission in the NICU, stored in the NICU databases and retrieved for data analysis. The following individual characteristics and perinatal variables were considered: gender, multiple birth, gestational age, birth weight, small for gestational age (SGA: birth weight below the 10th centile), low 5-min Apgar score $(<7)$, intracranial haemorrhage grade 3 and 4 (ICH) [32], periventricular leucomalacia (PVL), bronchopulmonary dysplasia (BPD; oxygen dependency at 36 weeks postconceptional age or at 28 days of life), ante- or postnatal use of steroids and length of stay in NICU.

\section{Assessment at the age of 5 years}

Clinical assessments were carried out on the health and neurological functioning of the children (not reported in this article) and four developmental domains: cognition, language, motor functioning and behaviour. A paediatrician, a child psychologist and a paediatric physical therapist assessed the children. Appointments were scheduled at random.

Cognitive development was assessed with the Revised Amsterdam Children's Intelligence Test (RAKIT) for children aged 4-11 years (short version). This version has a correlation of 0.93 with the full-scale test. The concurrent validity with the Wechsler Intelligence Scale for Children-Revised (WISC-R) is 0.86 for total IQ (Intelligent Quotient) [3].

This test included logical reasoning, word knowledge, visual-motor integration and word fluency. It also included visual synthesis for children younger than 5.2 years and visual analysis and memory for children aged 5.2 years or older. The norm score (IQ score) of the test is 100 with a standard deviation (SD) of 15. All scores higher or equal to 85 are classified as normal, while scores below 1 or 2 SD's are classified as mild or severe cognitive problems, respectively.

The Dutch Language Screening Test assessed language and speech. This test consists of 39 items covering the use of vocabulary, comprehension, memory and production of language, use of plurals, prepositions and pronunciations. The total score varies from 0 to 52 , with a score $\leq 18$ considered to be normal, that of 19-25 considered to indicate mild problems and that of $>25$ to indicate severe problems [7]. The Movement Assessment Battery for Children (Movement ABC) was used to assess motor skills. A total motor impairment score (range: 0-40) was computed by summing the scores on all motor tasks. A total score $\leq 10.5$ ( 15 th centile) was considered to be normal, from 11.0 through to 17.0 (5th centile) considered to indicate children at risk and $>17.0$ to indicate abnormal motor development [11, 23].

To assess behavioural outcomes, we used the Child Behaviour Checklist for children aged 4-18 years (CBCL). This is a standardized parental questionnaire used to describe the skills and behavioural problems of children. It comprises 113 descriptions of behavioural problems, with each description scored as: 0 (not true), 1 (somewhat or sometimes true) or 2 (very true or often true). A total problem score is obtained by summing all items. The severity of the behaviour problems can be the borderline and clinical cut-off point, corresponding with standardized norm scores of 60 and 63, respectively [1, 30]. A normal score is $<60$, a mild problematic score is $\geq 60$ and $\leq 63$, and a severe problem score is $>63$.

\section{Statistical analysis}

In order to compare the results of the follow-up assessments and school outcomes, we cross-tabulated categorical data originating from the individual developmental test results of the children with school outcomes (normal or problematic). Normal follow-up outcomes were defined as four normal developmental scores or only one mild developmental problem score. Problematic follow-up outcomes were defined as two mild developmental problem scores, one severe developmental problem score or two or more severe developmental problem scores.

Cross-tabulation was also used to describe the relation between the follow-up assessment outcomes and the school outcomes and the nominal variables (chi-square for testing). A one-way analysis of variance was used to assess within each of the follow-up outcomes the differences between the two types of school outcomes on the interval variables ( $F$ test for testing). The general linear model (GLM) was used for multivariate testing of the differences between the two school outcome groups within each of the two follow-up outcome groups.

\section{Results}

Of the 498 children included in this follow-up study, 143 (29\%) were not assessed for various reasons (Table 1). Consequently, all outcome data, including developmental 
Table 1 Eligible and assessed children

\begin{tabular}{|c|c|c|c|c|}
\hline & $n$ & Percentage & $n$ & Percentage \\
\hline Cohort 1992-1994 & 768 & 100 & & \\
\hline Died & 131 & 17 & & \\
\hline Excluded because of participation in an other study & 46 & 6 & & \\
\hline Excluded because of severe handicap and/or in Special Schools & 33 & 4 & & \\
\hline Children of non-Dutch parents & 60 & 8 & & \\
\hline Eligible & 498 & 65 & 498 & 100 \\
\hline Address unknown & & & 25 & 5 \\
\hline $\begin{array}{l}\text { Moved outside the } \\
\text { country }\end{array}$ & & & 5 & 1 \\
\hline Treated in another hospital & & & 6 & 1 \\
\hline Impossibility to make a convenient appointment & & & 29 & 6 \\
\hline Refusal by the parents & & & 38 & 8 \\
\hline Assessment not fully performed & & & 40 & 8 \\
\hline Assessed & & & 355 & 71 \\
\hline
\end{tabular}

data, were collected on 355 children at the age of 5 years. No significant differences were found in perinatal data between assessed, partly assessed and unassessed children, with the exception of multiple births in that they were overrepresented in the assessed group [14].

Mutual correlations between child characteristics and perinatal variables were present but rather low. The percentage of children with all follow-up assessment results being normal or with only one mild developmental problem score was $64 \%(n=228) ; 36 \%(n=127)$ of the children had at least two mild problems or one or more severe problems according to the four developmental tests. No school problems were reported for 222 children (63\%), while 133 children (37\%) were reported to school problems as reflected in the need for special help (remedial teaching or other forms of extra help or specialized mainstream education). One hundred and seventy-five children (49\% of the study group) had normal school outcomes and normal follow-up outcomes and 80 children $(23 \%$ of the study group) had problematic follow-up outcomes and problematic school outcomes. These results show that for
$72 \%(n=255)$ of the children there was a positive relation between school outcomes and the results of the follow-up assessments. Fifty-three children (15\% of the study group) had school problems, while their developmental test scores were normal, and 47 children (13\% of the study group) did not receive any extra help at school, although they had test scores that fell in the problematic range. However, for 100 children $(28 \%)$ there was no concordance between the school outcomes and follow-up assessment results (Table 2). A significant difference $\left(\chi^{2}=66.44, p=0.00\right)$ was found between the two school outcome groups, with more developmental problems in the school problem group. Children who received special help at school although they had obtained normal follow-up assessment results, differed significantly from the children with normal follow-up results without special assistance. This subgroup comprised more boys and SGA children who had lower Movement $\mathrm{ABC}$ scores (motor skills) and, in particular, lower language screening test scores.

For children who did not receive any extra help at school, even though problematic follow-up assessments
Table 2 Follow-up outcomes versus school outcomes

\begin{tabular}{llll}
\hline School outcomes: & $\begin{array}{l}\text { Normal: } n=222 \\
(100 \%)\end{array}$ & $\begin{array}{l}\text { Problematic: } \\
n=133(100 \%)\end{array}$ & $\begin{array}{l}\text { Total: } n=355 \\
(100 \%)\end{array}$ \\
\hline $\begin{array}{l}\text { Follow-up outcomes: } \\
\text { Normal: } n=228(64 \%)\end{array}$ & & & \\
$\quad \begin{array}{l}\text { Four normal developmental scores } \\
\text { One mild developmental problem score }\end{array}$ & $124(56 \%)$ & $26(20 \%)$ & \\
Subtotal & $175 \rightarrow$ & $27(20 \%)$ & $49 \%$ \\
& & $53 \rightarrow$ & $15 \%$ \\
$\begin{array}{l}\text { Problematic: } n=127(36 \%) \\
\text { Two mild developmental problem scores }\end{array}$ & $8(4 \%)$ & $10(7 \%)$ & \\
$\quad \begin{array}{l}\text { One severe developmental problem score } \\
\text { Two or more severe developmental }\end{array}$ & $36(16 \%)$ & $54(41 \%)$ & $13 \%$ \\
$\quad$ problem scores & $3(1 \%)$ & $16(12 \%)$ & $23 \%$ \\
Subtotal & $47 \rightarrow$ & $80 \rightarrow$ & \\
& & & \\
\end{tabular}


Table 3 Means, standard deviations (SD) and one-way analyses of variance for normal and problematic school outcomes

\begin{tabular}{|c|c|c|c|c|c|c|}
\hline & \multirow[t]{3}{*}{ Follow-up outcomes } & \multicolumn{5}{|c|}{ School outcomes } \\
\hline & & \multicolumn{2}{|l|}{ Normal } & \multicolumn{2}{|c|}{ Problematic } & \multirow[t]{2}{*}{$F$} \\
\hline & & Mean & SD & Mean & SD & \\
\hline \multirow[t]{2}{*}{ Gestational age } & Normal & 30.08 & 1.85 & 30.50 & 1.54 & 2.33 \\
\hline & Problematic & 30.69 & 2.01 & 29.90 & 2.30 & $3.82 *$ \\
\hline \multirow[t]{2}{*}{ Birth weight } & Normal & 1286.24 & 319.20 & 1314.28 & 307.09 & .32 \\
\hline & Problematic & 1225.09 & 306.43 & 1241.22 & 364.36 & .06 \\
\hline \multirow[t]{2}{*}{ NICU stay } & Normal & 27.20 & 22.33 & 25.07 & 16.53 & .42 \\
\hline & Problematic & 26.91 & 20.82 & 36.94 & 37.17 & 2.89 \\
\hline \multirow[t]{2}{*}{ RAKIT IQ } & Normal & 104.82 & 11.77 & 102.39 & 10.64 & 1.83 \\
\hline & Problematic & 95.17 & 12.19 & 86.74 & 12.92 & $13.19 * * *$ \\
\hline \multirow[t]{2}{*}{ Movement $\mathrm{ABC}$} & Normal & 6.11 & 4.31 & 7.81 & 4.23 & $6.44 *$ \\
\hline & Problematic & 15.30 & 7.71 & 18.38 & 9.10 & $3.80^{*}$ \\
\hline \multirow[t]{2}{*}{ Language score } & Normal & 8.29 & 4.68 & 10.78 & 5.74 & $10.48 * * *$ \\
\hline & Problematic & 11.55 & 7.86 & 15.48 & 8.48 & $6.73 *$ \\
\hline \multirow[t]{2}{*}{ CBCL Total problem score } & Normal & 47.22 & 8.83 & 48.06 & 8.25 & .38 \\
\hline & Problematic & 55.32 & 10.70 & 55.05 & 12.06 & .02 \\
\hline
\end{tabular}

${ }^{*} p<0.05, * * * p<0.001$

were found, the results differed significantly from those who did receive extra help. This subgroup was less preterm, had higher Apgar scores, had had BPD less often and was treated less frequently with steroids during the neonatal period. Their scores on the Movement ABC, the language screening test and, in particular on the RAKIT (intelligence test) were better (Tables 3 and 4). Within each of the follow-up assessment groups (normal or problematic assessment results) the MANOVA showed significant differences between the two school outcome groups $(F=3.47, p<0.01, d f=6.22$ and $F=3.29, p<0.01, d f=6.12$, respectively).
Table 4 Comparison of child's characteristics, perinatal data and parents' education with normal and problematic school outcomes

\begin{tabular}{|c|c|c|c|c|}
\hline & \multirow[t]{2}{*}{ Follow-up outcomes } & \multicolumn{2}{|c|}{ School outcomes } & \multirow[t]{2}{*}{$x^{2}$} \\
\hline & & $\begin{array}{l}\text { Normal } \\
\text { Percentage }\end{array}$ & $\begin{array}{l}\text { Problematic } \\
\text { Percentage }\end{array}$ & \\
\hline \multirow[t]{2}{*}{ Male } & Normal & 42 & 57 & $4.10^{*}$ \\
\hline & Problematic & 64 & 63 & .01 \\
\hline \multirow[t]{2}{*}{ Multiple birth } & Normal & 35 & 44 & 1.43 \\
\hline & Problematic & 32 & 36 & .20 \\
\hline \multirow[t]{2}{*}{ SGA } & Normal & 23 & 37 & $4.29 *$ \\
\hline & Problematic & 4 & 25 & 3.25 \\
\hline \multirow[t]{2}{*}{ Apgar score } & Normal & 15 & 7 & 2.27 \\
\hline & Problematic & 47 & 31 & $8.73 *$ \\
\hline \multirow[t]{2}{*}{$\mathrm{ICH}$} & Normal & 5 & 0 & 2.55 \\
\hline & Problematic & 4 & 6 & .21 \\
\hline \multirow[t]{2}{*}{ PVL } & Normal & 2 & 2 & .04 \\
\hline & Problematic & 2 & 6 & 1.09 \\
\hline \multirow[t]{2}{*}{ BPD } & Normal & 4 & 6 & .24 \\
\hline & Problematic & 0 & 16 & $8.40 * *$ \\
\hline \multirow[t]{2}{*}{ Neonatal steroids } & Normal & 1 & 0 & .31 \\
\hline & Problematic & 0 & 11 & $5.62 *$ \\
\hline \multirow[t]{2}{*}{ Parents education-high } & Normal & 42 & 36 & .73 \\
\hline & Problematic & 39 & 26 & 2.15 \\
\hline \multirow[t]{2}{*}{ Parents education-middle } & Normal & 47 & 51 & .11 \\
\hline & Problematic & 38 & 48 & .90 \\
\hline \multirow[t]{2}{*}{ Parents education-low } & Normal & 11 & 13 & .18 \\
\hline & Problematic & 23 & 26 & .10 \\
\hline
\end{tabular}




\section{Discussion}

The developmental skills of children are largely expressed in school functioning [25]. Therefore, it would be expected that there is a great concordance between the assessments of the NICU follow-up teams and school teams with respect to the identification of children who need special assistance at school. The results of this study support this expectation with respect to children with good developmental outcome assessments and those with obvious problematic developmental outcomes. While the latter group mainly consisted of children with very low gestational ages and/or serious perinatal problems, some were being faced with the direct adverse consequences of the use of neonatal steroids [36]. It is likely that the problems of these children and the genuine concern of parents and teachers has offered them the extra attention and assistance they required.

Children with relatively normal developmental outcomes who, notwithstanding this, received extra help at their schools, still had language and/or motor problems that apparently interfered with school functioning, thereby causing schoolteachers to provide them with extra attention and help. The overrepresentation of boys in this group, as in both groups with problematic developmental outcomes, is a frequent finding [8] and because their behavior is often more demonstrative there is a stronger need to deal with. More children who were SGA were also found in this group. A number of these were still small at the age of 5 years, which may have led to overprotection or the conviction that the child needs more time or help to be ready for reading, writing or arithmetic $[10,21]$. Further research should reveal if the problems of this latter group of children are attributable to not being ready for learning (pre) academic skills or to still being too playful, or whether it concerns serious learning and developmental problems.

The limited number of children with developmental problems who were not signalled by the school did not have special characteristics with the exception of having slightly better developmental outcomes and/or having not been born extremely premature, having not been subjected to neonatal steroids and/or having had a somewhat less complicated neonatal period. It is possible that their developmental problems did not interfere with school functioning or they were able to compensate for them, but it is also possible that their parents and/or teachers did not signal their problems adequately. Parents are sometimes very relieved that the first difficult and worrisome years are over and unconsciously cut themselves off from new problems or both parents and teachers lower their expectations and demands because of overprotection. We did not find that less well-educated parents had more difficulties in mobilizing extra help for their children than relatively well- educated parents. Children of the former displayed developmental problems more often, but they received extra help and assistance in the same ratio as children of relatively more highly educated parents. Based on this line of reasoning a possible overrepresentation of children of less well-educated parents in the unassessed group would not change the degree of concordance between the follow-up results and school outcomes.

One may question whether our developmental tests were sensitive enough to register minor neurological signs. In the overall study the paediatrician did a neurological examination (the modified Touwen examination) [28]. This examination classified $120(34 \%)$ of the children participating in this study with neurological problems (disabling cerebral palsy, non-disabling cerebral palsy, minimal neurological dysfunction and gross motor retardation). Ninety-five $(93 \%)$ of these children were also classified as problematic by one or more of the other instruments. While these neurological data provide a more complete picture, they do not improve the degree of concordance between school outcome and follow-up outcome (70\%).

Of the preterm children tested at age 5 years, one-half were found to have problems in the developmental assessments or in school functioning. This outcome confirms the findings of others that follow-up research in more than one developmental domain in combination with school outcomes shows a more problematic outcome picture [29].

Schools are doing quite well in identifying children with and without developmental problems, but the need for longitudinal multidisciplinary follow-up programmes in different developmental domains remains. Information that promotes the understanding of the development of these children during their school career provides schools and parents with more tools for early detection and will facilitate the design and evaluation of intervention programmes.

Acknowledgements The authors thank Ina Kloosterman-Boerrigter (TNO Prevention and Health, Leiden), Louis Kollée, Maria Nijhuis-van der Sanden and Simone Knuijt (University Medical Centre Nijmegen), Aleid van Wassenaer, Adri Ilsen, Rinske Breur-Pieterse and Karen Koldewijn (Academic Medical Centre, Amsterdam), Jan Buijs and Marion Wit (Máxima Medical Centre, Veldhoven) for their participation in the Validation Study Group.

\section{References}

1. Achenbach TM (1991) Manual for the child behavior checklist 4 18 and revised behavior profile. University of Vermont, Burlington

2. Bhutta AT, Anand KJ (2002) Vulnerability of the developing brain. Neuronal mechanisms. Clin Perinatol 29:272-357

3. Bleichrodt N, Drenth PJ, Zaal JN, Resing WC (1984) Revisie Amsterdamse Kinder Intelligentie Test. Instructie, normen, psychometrische gegevens. Swets \& Zeitlinger, Lisse

4. Chapieski ML, Evankovich KD (1997) Behavioral effects of prematurity. Semin Perinatol 21:221-239 
5. Driessen GW (1993) Social or ethnic determinants of educational opportunities? Results from the evaluation of the education priority policy programme in the Netherlands. Stud Educ Eval 19:265-280

6. Escobar GJ, Littenberg B, Petitti DB (1991) Outcome among surviving very low birthweight infants: a meta-analysis. Arch Dis Child 66:204-211

7. Gerritsen FM (1988) VTO Taalscreening 3- tot 6-jarigen: de ontwikkeling van een taalscreeningsinstrument voor gebruik in de jeugdgezondheidszorg. Swets \& Zeitlinger, Amsterdam/Lisse

8. Graham P (1979) Epidemiological studies. In: Quay H, Werry J (eds) Psychopathological disorders of childhood. Wiley, New York, pp 455-494

9. Gressens P, Rogido M, Paindaveine B, Sola A (2002) The impact of neonatal intensive care practices on the developing brain. J Pediatr 140:646-653

10. Gutbrod T, Wolke D, Soehne B, Ohrt B, Riegel K (2000) Effects of gestation and birth weight on the growth and development of very low birthweight small for gestational age infants: a matched group comparison. Arch Dis Child Fetal Neonatal Ed 82:F208-F214

11. Henderson SE, Sugden DA (1992) The movement assessment battery for children. Psychological Corp, San Antonio

12. Hille ET, Den Ouden AL, Bauer L, van den Oudenrijn C, Brand R, Verloove-Vanhorick SP (1994) School performance at nine years of age in very premature and very low birth weight infants: Perinatal risk factors and predictors at five years of age. J Pediatr $125: 426-434$

13. Horwood LJ, Mogridge N, Darlow BA (1998) Cognitive, educational, and behavioural outcomes at 7 to 8 years in a national very low birthweight cohort. Arch Dis Child Fetal Neonatal Ed 79:F12-F20

14. de Kleine MJ, den Ouden AL, Kollée LA, Nijhuis-van der Sanden MW, Sondaar M, van Kessel-Feddema BJ, Knuijt S, van Baar AL, Ilsen A, Breur-Pieterse R, Briët JM, Brand R, Verloove-Vanhorick SP (2003) Development and evaluation of a follow up assessment of preterm infants at five years of age. Arch Dis Child 88:870-875

15. Leonard CH, Piecuch RE (1997) School age outcome in low birth weight preterm infants. Semin Perinatol 21:240-253

16. Luoma L, Herrgard E, Martikainen A, Ahonen T (1998) Speech and language development of children born at 32 weeks' gestation: a 5-year prospective follow-up study. Dev Med Child Neurol 40:380-387

17. Mc Cormick MC (1993) Has the prevalence of handicapped infants increased with improved survival of the very low birth weight infant? Clin Perinatol 20:263-277

18. McGrath MM, Sullivan MC, Lester BM, Oh W (2000) Longitudinal neurologic follow-up in neonatal intensive care unit. Survivors with various neonatal morbidities. Pediatrics 106:1397-1405

19. Ornstein M, Ohlson A, Edmonds J, Asztalos E (1991) Neonatal follow-up of very low birthweight/extremely low birthweight infants to school age; a critical overview. Acta Paediatr Scand 80:741-748
20. Perlman JM (2001) Neurobehavioral deficits in premature graduates of intensive care. Potential medical and neonatal environmental risk factors. Pediatrics 108:1339-1348

21. Qvigstad E, Verloove-Vanhorick SP, Ens-Dokkum MH, Schreuder AM, Veen S, Brand R, Oostdijk W, Ruys JH (1993) Prediction of height achievement at five years of age in children born very preterm or with very low birth weight: continuation of catch-up growth after two years of age. Acta Paediatr 82:444-448

22. Saigal S (2000) Follow-up of very low birthweight babies to adolescence. Semin Neonatol 5:107-118

23. Smits-Engelsman BC (1998) Movement ABC; Nederlandse handleiding (Dutch manual Movement ABC). Swets \& Zeitlinger, Lisse

24. Sommerfelt K (1998) Long-term outcome for non-handicapped low birth weight infants - is the fog clearing? Eur J Pediatr 157:1-3

25. Sternberg RJ, Beyond IQ (1985) A triarchic theory of human intelligence. Cambridge University Press, Cambridge

26. Sykes DH, Hoy EA, Bill JM, McClure BG, Halliday HL, Reid M (1997) Behavioural Adjustment in School of Very Low Birthweight Children. J Child Psychol Psychiatry 38:315-325

27. Taylor HG, Burant CJ, Holding PA, Klein N, Hack M (2002) Sources of variability in sequelae of very low birth weight. Child Neuropsychol 8:163-178

28. Touwen BC (1989) Examination of the child with minor neurological dysfunction. Clin Dev Med 11:353-363

29. Van Baar AL, van Wassenaer AG, Briët JM, Dekker FW, Kok JH (2005) Very preterm birth is associated with disabilities in multiple developmental domains. J Pediatr Psychol 30:247-255

30. Verhulst FC, van der Ende J, Koot HM (1996) Manual for the child behavior checklist/4-18 (Dutch version). Department of child psychiatry, Sophia children's hospital/Academic hospital Rotterdam/Erasmus university, Rotterdam

31. Vohr BR, Msall ME (1997) Neuropsychological and functional outcomes of very low birth weight infants. Semin Perinatol 21:202-220

32. Volpe JJ (2001) Neurology of the newborn. Saunders, Philadelphia

33. Walther FJ, den Ouden AL, Verloove-Vanhorick SP (2000) Looking back in time: outcome of a national cohort of very preterm infants born in The Netherlands in 1983. Early Hum Dev 59:175-191

34. Weindrich D, Jennen-Steinmetz C, Laucht M, Schmidt MH (2003) Late sequelae of low birthweight: mediators of poor school performance at 11 years. Dev Med Child Neurol 45:463469

35. Werner EE (1997) Vulnerable but invincible: high-risk children from birth to adulthood. Acta Paediatr 422:103-105

36. Wood NS, Costeloe K, Gibson AT, Hennessy EM, Marlow N, Wilkinson AR (2005) The epicure study: associations and antecedents of neurological and developmental disability at 30 months of age following extremely preterm birth. Arch Dis Child Fetal Neonatal Ed 90:134-140 